\title{
Early Feeding Practices and Body Mass Index Z-Score among Saudi Preschoolers: A Cross-Sectional Study
}

Rana Mosli ( $\square$ ranamosli@gmail.com )

Research

Keywords: Complementary Feeding, Breastfeeding, Fruit Juice, Bottle, Birthweight, Body Mass Index Z-Score, Preschool

Posted Date: September 7th, 2021

DOl: https://doi.org/10.21203/rs.3.rs-850429/v1

License: @ (1) This work is licensed under a Creative Commons Attribution 4.0 International License. Read Full License 


\section{Abstract}

Objectives

To characterize early feeding practices among mothers in Saudi Arabia and examine their associations with child birthweight and BMI z-score (BMIz) at preschool.

Study Design

Cross-sectional study.

Methods

Mother-child dyads $(\mathrm{n}=209)$ were recruited from different preschools around the city of Jeddah. Mothers completed the study questionnaire over the telephone and preschoolers' anthropometric measurements were objectively measured. Descriptive statistics were used to characterize early feeding practices. Bivariate analyses and linear regression were used to examine the association of early feeding practices with child birthweight and BMlz at preschool.

Results

The majority of mothers $(92.3 \%)$ initiated breastfeeding, with an average duration of 9.34 months $(S D=8.04)$. About half of the mothers reported that they have offered fruit juice and/or date syrup-milk mixture in a baby bottle ( $52.2 \%$ and $45.9 \%$ respectively), with an average duration of 11.5 months $(S D=7.73)$ and 5.90 months $(S D=6.13)$, respectively. Children who were offered fruit juice and/or date syrup-milk mixture in a baby bottle had significantly lower birthweights compared to children who were not (M=2.79, SD= 0.59 vs. $M=3.06, S D=0.69, P<0.01$ and $M=2.79, S D=0.67$ vs. $M=3.03, S D=0.62, P<0.01$, respectively). There was a negative association between introducing fruit juice in a baby bottle and child BMlz at preschool (b: $0.18,95 \%$ confidence interval (Cl): -0.83 , -0.11); This association was not significant after adjusting for child birthweight and other covariates (b: $-0.10,95 \%$ Cl: $-0.64,0.09$ ).

Conclusion

Longitudinal and interventions studies are needed to inform counseling guidelines and community campaigns in order to improve early feeding practices in the region.

\section{Introduction}

Feeding practices during early years may have long-lasting influences on eating behaviors, growth patterns and body mass index (BMI) trajectory. ${ }^{1}$ Early feeding practices in the Middle East have been widely explored. Mothers in the region have shown strong commitment to breastfeeding as a result of religious beliefs; On average, two-thirds of children are breastfed beyond the first year of life. ${ }^{2,3}$ However, early complementary feeding is common among Middle Eastern/Arab mothers stemming from cultural and familial traditions. $^{2}$ On average, only around $24 \%$ of infants in the region are exclusively breastfed. ${ }^{3,4}$ First complementary foods include juice and date products (e.g., date syrup mixed with milk), which are often introduced within the first few weeks of life..$^{2,5}$

Current recommendations regarding fruit juice consumption among infants state that fruit juice offer no additional nutritional benefits and should not be introduced prior to one year of age unless clinically indicated. ${ }^{6}$ For toddlers between one and three years of age, fruit juice should not be offered in bottles or easily transportable cups, and intake should not exceed four ounces per day. ${ }^{6}$ The growing concern surrounding juice intake in children is related to it being easily overconsumed when offered, and to the negative consequences of overconsumption. ${ }^{6}$ Overconsumption of fruit juice can lead to displacement and insufficient intake of nutrients from other food sources, including protein and calcium from milk, as well as short stature, excessive sugar intake, diarrhea and tooth decay. ${ }^{7-10}$ Evidence surrounding the association between fruit juice consumption and overweight risk among children is conflicting. ${ }^{11}$ While one study reported that children who consistently drink juice at two years of age might have higher odds of overweight at age four, ${ }^{12}$ others found that consumption of fruit juice is associated with minimal, non-clinically significant weight gain in children ages one to six years. ${ }^{13}$ 
Offering sugary liquids such as fruit juice in baby bottles has been observed among a large proportion (73\%) of a cohort of Hispanic mothers. ${ }^{14}$ However, this practice has not been adequately evaluated in Middle Eastern/Arab populations. Feeding infants from a bottle might be associated with greater liquid intake compared to when infants are fed from the breast or a cup. ${ }^{15}$ Thus, offering sugary liquids, such as juice and date syrup-milk mixture, in bottles might lead to overconsumption. Furthermore, mothers have previously reported that their child's birthweight may affect their decisions regarding solid food introduction. ${ }^{16}$ However, the association between child's birthweight and offering sugary liquids in baby bottles has not been sufficiently explored.

The current literature is lacking data regarding the prevalence of offering sugary drinks (e.g., fruit juice and date syrup-milk mixture) in bottles in Middle Eastern/Arab countries such as Saudi Arabia (SA). Furthermore, the association of intake of sugary drinks during infancy and offering these drinks in baby bottles with child birthweight and body mass index (BMI) at preschool is underdeveloped. The objective of this study was to characterize early feeding practices among a sample of mothers in SA and examine their association with child birthweight and child BMI at preschool while adjusting for various covariates.

\section{Methods}

\section{Study Protocol}

A total of 209 mother-child dyads were recruited from different preschools around the city of Jeddah, SA that were randomly selected based on location; Two preschools were located in the Eastern area, two in the Western area, two in the Northern area, and two in the Southern area. Four of the eight preschools were government-subsidized centers, and four were private preschools. An invitation to participate in the study was sent to all mothers via their children's backpacks. The invitation letter included a description of the study, screening items that assessed eligibility for participation, and the participation consent form. Mothers who were eligible to participate and returned signed consent forms were contacted by research assistants who completed the study questionnaire with them over the telephone. The study questionnaire was administered in Arabic and included questions that assessed early feeding practices and sociodemographic characteristics. The study questionnaire was pretested using a different sample consisting of 60 mothers of preschool children and was reviewed by an expert committee of four health care professionals. Minor clarifications were made to wording of questions based on comments from mothers and expert committee members.

About a week following questionnaire completion, the study team visited the preschools in order to obtain anthropometric measurements from children enrolled in the study. Study inclusion criteria were: Child is three to five years of age and is healthy with no serious medical problems or history of food allergies; Mother is fluent in Arabic. Ethical approval to conduct this study was obtained from the Unit of Biomedical Ethics at-_-_.

\section{Measures}

\section{Early Feeding Practices}

Mothers were asked if they had ever breastfed their child, followed by questions regarding the duration of breastfeeding, and the timing at which formula milk was introduced, if ever. Mothers were then asked questions regarding complementary feeding and the timing at which any foods or drinks other than milk and water were introduced. Then, mothers were asked the following regarding fruit juice, date syrup-milk mixture, and soda drinks: 1) If the drink was ever introduced in a baby bottle, 2) the child's age at which the drink was first offered in a baby bottle, and 3) the child's age at which offering the drink in a baby bottle was discontinued. The child's age at which the drink was first offered in a baby bottle and age at which offering the drink in a baby bottle was discontinued were later used to calculate "duration of offering drink in bottle".

Child BMI Z-Score (BMIz)

Children's weights and heights were measured by trained research assistants using standardized procedures. BMI was calculated for each child as weight (kg) divided by height2 (m2). ${ }^{17}$ The age- and sex-specific World Health Organization (WHO) growth standards and reference data were used to calculate BMIz for each child ${ }^{18,19}$ Weight and height data were missing for two children who have transferred to other schools, and these participants were therefore excluded from analyses involving child BMlz.

Birthweight and sociodemographic characteristics

Page $3 / 13$ 
Mothers reported their child's birthweight as well as data regarding sociodemographic characteristics, which included information about the child's sex and birthdate, the mother's birthdate, educational level, and employment status, and the family's total monthly income

( $\leq 10,000$ SR vs. $>10,000 \mathrm{SR})(10,000 \mathrm{SR}$ is equivalent to $2,666 \mathrm{USD}) .{ }^{20}$ Child and maternal age were calculated based on birthdates and dates of interviews.

\section{Statistical Analysis}

Analyses were conducted using IBM SPSS Statistics 21.0 (Armonk, NY, USA). Descriptive statistics, including means and standard deviations and frequencies and percentages, were used to describe the sample and early feeding practices. Pearson correlations were used to examine the association between various early feeding practices (e.g., breastfeeding duration and age of formula milk introduction).

Bivariate analyses, including independent samples t-test and Pearson correlations were used to examine the association between early feeding practices and child birthweight, and between early feeding practices and child BMIz at preschool. Then, in order to examine the adjusted association between early feeding practices and child BMIz at preschool, linear regression models were conducted. Only feeding practices that were significantly associated with child BMIz in bivariate analyses were inserted as predictors in regression models. Regression models were adjusted for child birthweight, child sex, breastfeeding duration maternal education, and total monthly income, each of which were previously found to be associated with both early complementary feeding and child BMI. ${ }^{16,21-24}$

\section{Results}

\section{Sample Characteristics}

Description of sample characteristics is shown in Table 1. Mean child birthweight was $2.93(S D=0.65)$. About half of the sample $(51.7 \%)$ was male, and mean child age was 4.79 years $(S D=0.79)$. More than half of participating mothers $(68.4 \%)$ had a college degree or higher, and around half (51.2\%) were housewives. About half of the sample (45.5\%) were considered "low-income", as they reported to have a total monthly income of 10,000 SR or less.

\section{Description of Early Feeding Practices}

The majority of mothers in our sample (92.3\%) initiated breastfeeding, with an average breastfeeding duration of 9.34 months (SD= 8.04). The average age at which formula milk and solid foods were introduced was 2.89 months $(S D=5.44)$ and 5.93 months (SD= $2.11)$, respectively. Mean child age at which fruit juice was introduced was 8.17 months $(S D=5.93)$, with $52.2 \%(n=109)$ of mothers reporting that they have offered fruit juice in a baby bottle at least once. Mean child age at which fruit juice was first offered in a baby bottle was 6.45 months $(S D=2.28)$, and the average duration for offering fruit juice in a baby bottle was 11.5 months $(S D=7.73)$. Only $1.00 \%(n=2.00)$ of mothers reported offering a soda drink in a baby bottle at least once, while $45.9 \%(n=96.0)$ reported offering date syrup-milk mixture in a baby bottle at least once. The average duration for offering date syrup-milk mixture in a baby bottle was 5.90 months $(S D=6.13)$ (Table 2$)$.

Breastfeeding duration was positively correlated with age of formula milk introduction; introducing formula milk later was associated with longer breastfeeding duration $(r=0.53, P<0.01)$. Age of formula milk introduction was positively correlated with duration of offering fruit juice in a baby bottle $(\mathrm{r}=0.21, P<0.05)$. Age of solid food introduction was positively correlated with age of fruit juice introduction $(\mathrm{r}=0.29, P<0.01)$, age at which fruit juice was introduced in a baby bottle $(\mathrm{r}=0.45, P<0.01)$, as well as age at which date syrup-milk mixture was introduced in a baby bottle $(r=0.26, P<0.05)$. Age of fruit juice introduction was positively correlated with age at which fruit juice was introduced in a baby bottle $(r=0.84, P<0.01)$. Furthermore, age at which date syrup-milk mixture was introduced in a baby bottle was positively correlated with duration of offering date syrup-milk mixture in a baby bottle $(\mathrm{r}=0.25, P<$ 0.05) (Table 3).

\section{Associations of Early Feeding Practices with Child Birthweight and BMI Z-score at Preschool}

Bivariate analyses showed that children who were offered fruit juice in a baby bottle had a significantly lower birthweight compared to children who were never offered fruit juice in a baby bottle $(M=2.79, S D=0.59$ vs. $M=3.06, S D=0.69, P<0.01)$. Likewise, children who 
were offered date syrup-milk mixture in a baby bottle had a significantly lower birthweight compared to children who were never offered date syrup-milk mixture in a baby bottle $(M=2.79, S D=0.67$ vs. $M=3.03, S D=0.62, P<0.01)$. Children who were offered fruit juice in a baby bottle had a significantly lower BMI z-score at preschool compared to children who were never offered fruit juice in a baby bottle $(M=-0.06, S D=1.41$ vs. $M=0.42, S D=1.22, P<0.05)$. There was no significant association between offering date syrupmilk mixture in a baby bottle and BMI z-score at preschool.

Breastfeeding duration and age of fruit juice introduction were each positively correlated with child birthweight $(\mathrm{r}=0.14, P<0.05$, and $\mathrm{r}=0.16, P<0.01$, respectively). Age of solid food introduction and age of fruit juice introduction were each positively correlated with BMI z-score at preschool ( $r=0.19, P<0.01$, and $r=0.18, P<0.05$, respectively)

Regression analysis showed that offering fruit juice in a bottle was associated with lower child BMIz at preschool (b: $0.18,95 \%$ confidence interval (Cl): -0.83, -0.11). However, this association was not significant after adjusting for child birthweight, child sex, breastfeeding duration, maternal education, and family monthly income (b: $-0.10,95 \% \mathrm{Cl}$ : $-0.64,0.09)$. Age of solid food introduction was associated with higher BMlz at preschool (b: $0.19,95 \% \mathrm{Cl}: 0.03,0.20)$, and this associations did not meaningfully change after adjusting for covariates (b: $0.18,95 \% \mathrm{Cl}: 0.03,0.18$ ). Furthermore, age of fruit juice introduction was associated with higher BMIz at preschool (b: $0.18,95 \% \mathrm{Cl}: 0.00,0.06)$. However, this association was not significant after adjusting for covariates $(\mathrm{b}: 0.12,95 \% \mathrm{Cl}$ : $-0.00,0.06)$ (Table 5).

\section{Discussion}

This observational study explored early feeding practices among a sample of 209 Saudi mothers and examined associations with child birthweight and BMIz at preschool. As previously reported in other countries in the region, prevalence of breastfeeding initiation in our sample $(92.3 \%)$ is relatively high, and average breastfeeding duration $(9.34$ months, $S D=8.04)$ is longer than what was reported elsewhere. $3,4,25-27$ On the other hand, the prevalence of offering sugary liquids in a baby bottle is concerning; About half of mothers in our sample reported offering fruit juice and date syrup-milk mixture in a baby bottle at least once. However, a higher percentage of mothers $(73 \%)$ reported adhering to this practice in El Salvador. ${ }^{14}$ The average duration of consuming fruit juice and date syrup-milk mixture in a baby bottle is also troubling (11.5 and 5.90 months on average, respectively), since offering sugary drinks in a baby bottle has been previously associated with overconsumption, excessive sugar intake, diarrhea and tooth decay. ${ }^{6-10}$

In line with findings from previous studies, our study found that introducing formula milk at an older age was associated with longer breastfeeding duration. ${ }^{28}$ We also found that introducing formula milk at an older age was associated with consumption of fruit juice in a bottle for a longer duration, and introducing date syrup-milk mixture in a baby bottle at an older age was associated with consuming it in a bottle for a longer duration. This suggests that older infants may develop a stronger preference for consuming various types of sugary liquids in a baby bottle compared to younger infants. Previous research has shown that flavor programming among infants and preference for liquids is linked to infants' age. ${ }^{29}$ Additional research is needed to better understand the intercorrelation of various feeding practices and their interaction with child's age.

In our sample, children who were offered fruit juice or date syrup-milk mixture in a baby bottle had a lower birthweight. Birthweight has been also linked to early feeding practices in previous studies. However, cultural variations may exist; For example, higher birthweight was found to predict later initiation of complementary feeding in the US. ${ }^{24}$ While in European populations, pretem birth was associated with earlier complementary feeding. ${ }^{30}$ It is unknown whether mothers in the Middle Eastern region opt to introduce sugary liquids in bottles to lower birthweight infants in order to provide additional calories. Further qualitative studies are needed to assess caregivers' beliefs and perceptions towards various early feeding practices in order to inform more effective, culturallysensitive intervention programs.

Unadjusted analyses showed that offering fruit juice in a baby bottle was associated with lower BMIz at preschool. However, adjusting this association for child birthweight and other covariates resulted in the association becoming non-significant, indicating that it was at least partly explain by the covariates. Additionally, our results showed that age of fruit juice introduction was positively associated with child BMIz at preschool. However, this association also became non-significant after adjusting for covariates. Therefore, the association between later fruit juice introduction and higher BMIz at preschool could be explained by the child having a higher birthweight. ${ }^{30}$ On the contrary, later solid food introduction was associated with higher child BMIz at preschool even after adjusting for covariates. Additional studies are needed to examine various maternal and child behaviors related to later solid food 
introduction in order to better understand and explain the association between later solid food introduction and higher BMIz at preschool among.

Although early complementary feeding has been previously associated with greater adiposity during mid-childhood and adolescence in a US sample, ${ }^{31}$ different complementary feeding patterns may be unique to Middle Eastern/ Arab mothers. The association between these complementary feeding practices and long-term child outcomes need further evaluation; Longitudinal and interventions studies are warranted in order to inform effective counseling guidelines and community campaigns in the region.

To our knowledge, this study was the first in the region to evaluate certain early feeding practices including the introduction of sugary drinks in a baby bottle, and to examine associations with child birthweight and BMIz at preschool. Our study also included mothers from various backgrounds and socioeconomic levels. Additionally, anthropometric measurements were collected objectively by trained researchers. Limitations of our study include the relatively small sample size which might have affected our power to detect significant associations. Our early feeding data were obtained retrospectively and might have been subjected to recall bias. Prospective cohort studies with larger sample sizes are needed in order to confirm our findings and inform cross-cultural comparisons.

\section{Conclusion}

In summary, although breastfeeding initiation and duration was relatively high in our sample of Saudi mothers, introducing sugary drinks, including fruit juice and date syrup-milk mixture in a baby bottle appears to be a common practice. Child birthweight might

influence mothers' decisions around feeding practices. Future studies are needed to further characterize these practices and identify effects on long-term child outcomes and obesity risk.

\section{Declarations}

\section{Ethical Approval and Consent to participate}

This study was conducted according to the guidelines laid down in the Declaration of Helsinki and all procedures involving research study participants were approved by the Unit of Biomedical Ethics at King Abdulaziz University (reference number HA-02-J-008). Written informed consent was obtained from all subjects.

\section{Consent for publication}

The authors hereby give consent for publication

\section{Availability of data and materials}

The data that support the findings of this study are available on request from the corresponding author. The data are not publicly available due to privacy or ethical restrictions.

\section{Competing interests}

The authors have no competing interests to declare

\section{Funding}

Not applicable

\section{Authors' contributions}

RM designed the study, oversaw data collection, analyzed the data, wrote the manuscript, and approved the final version as submitted.

\section{Acknowledgements}

Not applicable

\section{Authors' information}


Rana H. Mosli, Clinical Nutrition Department, Faculty of Applied Medical Sciences, King Abdulaziz University, P.0. Box 80215, Jeddah 21589, KSA [aimuwseli@kau.edu.sa; ranamosli@gmail.com].

\section{References}

1. Thompson AL. Evaluating the pathways linking complementary feeding practices to obesity in early life. Nutrition Reviews. 2020;78:13-24.

2. Jessri M, Farmer AP and Olson K. A focused ethnographic assessment of middle eastern mothers' infant feeding practices in Canada. Maternal \& child nutrition. 2015;11:673-686.

3. Dop M-C and Benbouzin D. Regional features of complementary feeding in Mrica and the Middle East. Complementary feeding of young children in Africa and the middle East. 1999:43.

4. Alyousefi NA, Alharbi AA, Almugheerah BA, Alajmi NA, Alaiyashi SM, Alharbi SS and Alnoumasi ZK. Factors influencing Saudi mothers' success in exclusive breastfeeding for the first six months of infant life: a cross-sectional observational study. International Journal of Medical Research \& Health Sciences. 2017;6:68-78.

5. Aldossari A, Alshehri D, Alzahrani G, Almasoud S, Alaqeel $Y$ and Benajiba N. Insights into knowledge, attitude and practices on early complementary feeding of infants among Saudi mothers. Malaysian Journal of Nutrition. 2019;25.

6. Heyman MB and Abrams SA. Fruit juice in infants, children, and adolescents: Current recommendations. Pediatrics. $2017 ; 139$.

7. Behrendt A, Sziegoleit F, Müler-Lessmann V, Ipek-Ozdemir G and Wetzel WE. Nursing-bottle syndrome caused by prolonged drinking from vessels with bill-shaped extensions. ASDC Journal of Dentistry for Children. 2001;68:47-50.

8. Murray RD. 100\% fruit juice in child and adolescent dietary patterns. Journal of the American College of Nutrition. 2020;39:1227.

9. Dennison BA, Rockwell HL and Baker SL. Excess fruit juice consumption by preschool-aged children is associated with short stature and obesity. Pediatrics. 1997;99:15-22.

10. Hyams JS and Leichtner AM. Apple juice: an unappreciated cause of chronic diarrhea. American Journal of Diseases of Children. 1985;139:503-505.

11. Crowe-White K, O'Neil CE, Parrott JS, Benson-Davies S, Droke E, Gutschall M, Stote KS, Wolfram T and Ziegler P. Impact of $100 \%$ fruit juice consumption on diet and weight status of children: An evidence-based review. Critical Reviews in Food Science and Nutrition. 2016;56:871-84.

12. Shefferly A, Scharf RJ and DeBoer MD. Longitudinal evaluation of $100 \%$ fruit juice consumption on BMI status in 2-5-year-old children. Pediatric Obesity. 2016;3:221-7.

13. Auerbach BJ, Wolf FM, Hikida A, Vallila-Buchman P, Littman A, Thompson D, Louden D, Taber DR and Krieger J. Fruit juice and change in BMI: a meta-analysis. Pediatrics. 2017;139.

14. Achalu P, Bhatia A, Turton B, Luna L and Sokal-Gutierrez K. Sugary Liquids in the Baby Bottle: Risk for Child Undernutrition and Severe Tooth Decay in Rural El Salvador. International Journal of Environmental Research and Public Health. 2021;18:260.

15. Li R, Fein SB and Grummer-Strawn LM. Do infants fed from bottles lack self-regulation of milk intake compared with directly breastfed infants? Pediatrics. 2010;125:e1386-e1393.

16. Tully L, Allen-Walker V, Spyreli E, McHugh S, Woodside JV, Kearney PM, McKinley MC, Dean M and Kelly C. Solid advice: Complementary feeding experiences among disadvantaged parents in two countries. Maternal \& Child Nutrition. 2019;15:e12801.

17. Mosli RH, Miller AL, Peterson KE, Kaciroti N, Rosenblum K, Baylin A and Lumeng JC. Birth order and sibship composition as predictors of overweight or obesity among low-income 4- to 8-year-old children. Pediatric obesity. 2016;11:40-6.

Page $7 / 13$ 
18. Onis MD, Onyango AW, Borghi E, Siyam A, Nishida C and Siekmann J. Development of a WHO growth reference for schoolaged children and adolescents. Bulletin of the World health Organization. 2007;85:660-7.

19. World Health Organization. WHO child growth standards: length/height for age, weight-for-age, weight-for-length, weight-forheight and body mass index-for-age, methods and development. World Health Organization; 2006.

20. Garawi F, Ploubidis GB, Devries K, Al-Hamdan N and Uauy R. Do routinely measured risk factors for obesity explain the sex gap in its prevalence? Observations from Saudi Arabia. BMC public health 2015;15:254.

21. Amin TT, Al-Sultan AL and Ali A. Overweight and obesity and their relation to dietary habits and socio-demographic characteristics among male primary school children in Al-Hassa, Kingdom of Saudi Arabia. European Journal of Nutrition. 2008;47:310.

22. Ajami M, Abdollahi M, Salehi F, Oldewage-Theron $\mathrm{W}$ and Jamshidi-Naeini Y. The association between household socioeconomic status, breastfeeding, and infants' anthropometric indices. International journal of preventive medicine. 2018;9.

23. Shafer EF and Hawkins SS. The impact of sex of child on breastfeeding in the United States. Maternal and child health journal. 2017;21:2114-2121.

24. Odar Stough C, Khalsa AS, Nabors LA, Merianos AL and Peugh J. Predictors of exclusive breastfeeding for 6 months in a national sample of US children. American Journal of Health Promotion. 2019;33:48-56.

25. Li R, Perrine CG, Anstey EH, Chen J, MacGowan CA and Elam-Evans LD. Breastfeeding trends by race/ethnicity among US children born from 2009 to 2015. JAMA pediatrics. 2019;173:e193319-e193319.

26. Grandahl $\mathrm{M}$, Stern $\mathrm{J}$ and Funkquist E-L. Longer shared parental leave is associated with longer duration of breastfeeding: a cross-sectional study among Swedish mothers and their partners. BMC pediatrics. 2020;20:1-10.

27. Scott JA, Binns CW, Oddy WH and Graham KI. Predictors of breastfeeding duration: evidence from a cohort study. Pediatrics. 2006;117:e646-e655.

28. Hörnell A, Hofvander $Y$ and Kylberg E. Solids and formula: association with pattern and duration of breastfeeding. Pediatrics. 2001;107:e38-e38.

29. Mennella JA, Griffin CE and Beauchamp GK. Flavor programming during infancy. Pediatrics. 2004;113:840-845.

30. Zielinska MA, Rust P, Masztalerz-Kozubek D, Bichler J and Hamułka J. Factors influencing the age of complementary feedingA cross-sectional study from two European countries. International journal of environmental research and public health. 2019;16:3799.

31. Gingras V, Aris IM, Rifas-Shiman SL, Switkowski KM, Oken E and Hivert M-F. Timing of complementary feeding introduction and adiposity throughout childhood. Pediatrics. 2019;144.

\section{Tables}

Table 1. Sample Characteristics $(n=209)^{*}$ 


\begin{tabular}{|c|c|}
\hline Child Birthweight, M (SD) & $2.93(0.65)$ \\
\hline \multicolumn{2}{|l|}{ Child Sex, N (\%) } \\
\hline Male & $108(51.7)$ \\
\hline Female & $101(48.3)$ \\
\hline Child Age, M (SD) & $4.79(0.79)$ \\
\hline Maternal Age, M (SD) & $33.05(4.98)$ \\
\hline \multicolumn{2}{|l|}{ Maternal Education, N (\%) } \\
\hline$<$ College degree & $66(31.6)$ \\
\hline$\geq$ College degree & $143(68.4)$ \\
\hline \multicolumn{2}{|c|}{ Maternal Employment, N (\%) } \\
\hline Employed & $84(40.2)$ \\
\hline Housewife & $107(51.2)$ \\
\hline Student & $15(7.20)$ \\
\hline Other & $3(1.40)$ \\
\hline \multicolumn{2}{|c|}{ Total Monthly Income, N (\%) } \\
\hline$£ 10,000 \mathrm{SR}$ & $95(45.5)$ \\
\hline$>10,000 \mathrm{SR}$ & $114(54.5)$ \\
\hline
\end{tabular}

* Table showing means (M) and standard deviations (SD) or counts (n) and percentages (\%). 
Table 2. Description of Early Feeding Practices*

\section{Variable}

Ever breastfed, $\mathrm{n}(\%)$

$193(92.3)$

Yes

$16.0(7.70)$

No

Breastfeeding Duration, M (SD) $(n=199)$

$9.34(8.04)$

Age of formula introduction, M (SD) $(n=173)$

$2.89(5.44)$

Age of solid food introduction, M (SD)

$5.75(2.11)$

Age of fruit juice introduction, M (SD) $(n=199)$

$8.17(5.93)$

Ever offered fruit juice in bottle, $n(\%)$

109 (52.2)

Yes

$100(47.8)$

No

Age at which fruit juice was introduced in bottle $(n=109)$

$6.45(2.82)$

Duration of offering fruit juice in bottle $(n=109)$

$11.5(7.73)$

Ever offered soda drink in bottle, $\mathrm{n}(\%)$

$2.00(1.00)$

Yes

$207(99.0)$

No

Ever offered date syrup-milk mixture in bottle, $\mathrm{n}(\%)$

$96.0(45.9)$

Yes

$113(54.1)$

No

Age at which date syrup-milk mixture was introduced in bottle, M (SD) $(n=96)$

$3.22(3.02)$

Duration of offering date syrup-milk mixture in bottle, M (SD) $(n=96)$

$5.90(6.13)$

*Sample size equal to 209 unless otherwise indicated. Age and duration measured in months. 
Table 3. Association between Various Early Feeding Practices Assessed by Pearson Correlation

$\begin{array}{llll}\begin{array}{l}\text { Breastfeeding } \\ \text { Duration }\end{array} & \begin{array}{l}\text { Age of } \\ \text { formula } \\ \text { introduction }\end{array} & \begin{array}{l}\text { Age of solid } \\ \text { food } \\ \text { introduction }\end{array} & \begin{array}{l}\text { Age of fruit } \\ \text { juice } \\ \text { introduction }\end{array}\end{array}$

$\begin{array}{ll}\begin{array}{l}\text { Age at } \\ \text { which fruit }\end{array} & \begin{array}{l}\text { Duration } \\ \text { of } \\ \text { juice was } \\ \text { offering } \\ \text { introduced } \\ \text { fruit } \\ \text { in bottle } \\ \text { juice in } \\ \text { bottle }\end{array}\end{array}$

Age at

which

date

syrup-milk

mixture

was

introduced

in bottle

Duration

of offering

date syrupmilk mixture in bottle

Breastfeeding

Duration

Age of

formula

$0.53^{* *}$

introduction

Age of solid

food

introduction

Age of fruit

$-0.01$

$-0.14$

0.06

juice

introduction

Age at which

fruit juice

$-0.02$

0.06

was

introduced in

bottle

Duration of

offering fruit

0.15

$0.21^{*}$

$-0.15$

$-0.04$

$-0.06$

juice in bottle

Age at which

$-0.15$

$-0.06$

$0.26^{*}$

0.07

$-0.08$

$-0.08$

milk mixture

was

introduced in

bottle

Duration of

offering date

0.08

0.16

0.03

0.02

$0.23^{t}$

0.01

$0.25^{\star}$

syrup-milk

mixture in

bottle

${ }^{\mathrm{t}} \mathrm{P}$-value $<0.10 \quad{ }^{*} \mathrm{P}$-value $<0.05{ }^{* *} \mathrm{P}$-value $<0.01$ 
Table 4. Bivariate Association of Early Feeding Practices with Child Birthweight and BMlz at Preschool ${ }^{1}$

Association with Child Birthweight

Differences in Means

Ever breastfed

$2.95(0.65)$

$2.63(0.67)$

Yes

No

Ever offered fruit juice in bottle

Yes

No

Ever offered date syrup-milk mixture in bottle

Yes

No

Pearson Correlation

Breastfeeding Duration

Age of formula introduction

Age of solid food introduction

Age of fruit juice introduction

Age at which fruit juice was introduced in bottle

Duration of offering fruit juice in bottle

Age at which date syrup-milk mixture was introduced in

bottle

Duration of offering date syrup-milk mixture in bottle

${ }^{1}$ Body mass index z-score (BMIz). Differences in means examined using independent samples t-test.
$2.79(0.62)^{\star \star}$
0.05 (1.22)
$3.03(3.03)$
0.27 (1.43)
$0.42(1.22)$
3.06 (0.69)

0.09

$0.14^{*}$

0.00

0.07

$0.26^{\text {** }}$

$-0.22$

$-0.05$

0.11

$-0.09$

$-0.11$
Association with BMlz at Preschool

0.18 (1.31)

$-0.35(1.47)$

$-0.06(1.41)^{\star}$

$-0.01$

$0.19^{\star \star}$

$0.18^{*}$

$-0.02$

$-0.13$

$-0.10$ 
Table 5. Unadjusted and Adjusted Associations between Early Feeding Practices and BMIz at Preschool ${ }^{1}$

Unadjusted Association with BMlz at Preschool

Adjusted Association with BMlz at Preschool ${ }^{2}$

\section{Ever offered fruit juice in} bottle

Yes

No

Age of solid food introduction

Age of fruit juice introduction

$0.19(0.03,0.20)^{\star *}$

$0.18(0.00,0.06)^{\star \star}$

$-0.10(-0.64,0.09)$

1

$0.18(0.03,0.18)^{\star \star}$

$0.12(-0.00,0.06)$

${ }^{1}$ Body mass index z-score (BMlz).

${ }^{2}$ Regression models adjusted for child birthweight, child sex, breastfeeding duration, maternal education, and total monthly income.

${ }^{*}$ P-value $<0.05 \quad{ }^{* *}$ P-value $<0.01$ 